\title{
Ekonomik ve Finansal Ülke Risklerin Banka Karlılığına Etkisi'
}

\author{
DOI: 10.26466/opus.601090 \\ * \\ Zekai Șenol $^{*}$
}

* Dr. Öğr. Üyesi, Sivas Cumhuriyet Üniversitesi, İÏBF, Bankacılık ve Finans Bölümü. Sivas/Türkiye E-Posta: zsenol@cumhuriyet.edu.tr ORCID: 0000-0001-8818-0752

\section{Öz}

Bankalar finansal piyasalarda fon aktarım işlevi sağlarlar. Bankalar, fon sağlayanlardan mevduat yoluyla elde ettikleri kaynakları kredi olarak fon talep edenlere aktarırlar. Bankalar bu fonksiyonların gerçekleştirirken birçok etken, risk ve belirleyiciyle karşllaşmaktadırlar. Banka karlllıklarını, banka finansal ve organizasyonel yapısından kaynakl içsel faktörler, ekonomik, sosyal, siyasal, hukuksal etkenlerden kaynakl dışsal faktörler etkileyebilir. Bu çalışmada, 2001-2016 dönemleri arasında ve 44 ülke örnekleminde, banka karlllkkların etkileyen ekonomik ve finansal ülke riskleri araştırılmıştır. Panel veri analizi yapılan çalışmada, döviz kuru istikrarı, borç servisilihracat ve bütçe dengesi risklerinin banka karllıklarını negatif etkilediği, buna karşın cari denge/GSYÏH riskinin banka karlılı̆̆ını pozitif etkilediği görülmüş̧ür. Risk faktörlerinin etkisi bazı değişsenlerde pozitif diğgerlerinde ise negative görülmüştür. Bu durum, örneklem ülkelerindeki olumlu ya da olumsuz ekonomik ve finansal koşullardan ortaya çıkmıs olabilir. Ortaya çıkan sonuçlar ekonomik ve finansal ülke risklerinin banka karlllıklarını etkilediklerini ve banka yönetimlerinin içsel risk faktörlerinin yanında dışsal risk faktörlerini de risk yönetim süreçlerine dahil etmeleri gerektiğini göstermektedir.

Anahtar Kelimeler: Banka Karlılı̆̆ı, Ekonomik Riskler, Finansal Riskler Jel sinıflandırmasi: $\quad G 21, G 32, C 23$

\footnotetext{
${ }^{1}$ Bu çalışma, 02-04 Mayıs 2019 tarihlerinde Osmaniye'de düzenlenen 18. Uluslararası Işletmecilik Kongresinde sözlü olarak sunulmuş, daha sonra makaleye dönüştürülmüştür
} 


\title{
Impact of Economic and Financial Country Risks on Bank Profitability
}

\begin{abstract}
Banks carry out the fund transfer function in financial markets. Banks transfer the funds obtained from deposits as loans to those fund that demanded by in need of funds. While performing these functions, banks face many factors, risks and determinants. The Bank's profitability can be influenced by the internal factors arising from the financial and organizational structure of the bank and by external factors arising from economic, social, political and legal factors. In this study, the economic and financial country risks affecting bank profitability were investigated between the years of 2001-2016 and in the sample of 44 countries. In the study conducted in the panel data analysis, it was seen that the exchange rate stability, debt service as of export and budget balance risks had a negative effect on the bank profitability, whereas the current account as of GDP risk had a positive effect on bank profitability. The effect of risk factors is positive in some variables and negative in others. This may have arisen from positive or negative economic and financial conditions in the sample countries. The results show that economic and financial country risks affect bank profitability and that bank management should include external risk factors in their risk management processes as well as internal risk factors.
\end{abstract}

Keywords: $\quad$ Bank Profitability, Economic Risks, Financial Risks

Jel Classification: G21, G32, C23 


\section{Giriş}

Bankacılık, fon sağlayıcılardan belirli bir maliyetle ya da maliyetsiz olarak elde ettiği kaynakları belirli bir fazlalıkla fon talep edenlere aktaran, sahip olduğu fiziksel altyapısıyla çeşitli nitelikte hizmetler gerçekleştiren finansal kuruluşlardır. Bankalar finansal sistemin en eski ve en önemli kuruluşlarıdır. Finansal sistem içinde zamanla değişik nitelikte ve fonksiyonda birçok finansal kuruluş ortaya çıkmış olsa da, bankacılık halen finansal sistemin en temel kuruluşlarındandır.

Bankacılık, ekonomilerde tasarruf oranının artmasına, tasarruf bilincinin gelişmesine katkı sağlamaktadır. Bankalar, mevduat başta olmak üzere çeşitli araç ve yöntemlerle fon sağlayıcılardan finansal kaynakları toplarken bu kaynaklara faiz, kar payı gibi değişik isimler altında katma değer sağlamaktadır. Bankaların kaynak sahiplerine faiz, kar payı, kazanç şeklinde sundukları bu gelirlerden daha fazla yararlanmak isteyenler daha fazla tasarruf eğilimine yönelmektedirler.

Bankacılık atıl kaynakların üretken alanlara aktarılmasında önemli sorumluluklar üstlenmektedir. Bankalar fon sağlayanlardan elde ettikleri kaynakları başta kredi olmak üzere çeşitli yöntemlerle üretken alanlara aktarmaktadır. Bankalar, bu fonksiyonu gerçekleştirirken vade ve tutar ayarlama gerçekleştirmekte, risk yönetimi uygulamakta, aktardığı kredilerin izleme ve kontrolünü gerçekleştirmektedir. Yapılan bu işlemler bankaların önemli derecede riskler üstlendiklerini ortaya koymaktadır. Bu bakımdan bankalar likidite, kredi, faiz oran, döviz kur ve operasyonel gibi değişik özellikte risklerle karşılaşmaktadırlar.

Banka işletmeciliği genel özellikleri itibariyle risk yönetim faaliyetidir. Sistem özü itibariyle mevduat sağlama ve kredi aktarma şeklinde kısa ve kolay şekilde ifade edilmiş olsa bile, bankacılık çok değişik ve önemli nitelikte risklerle karşılaşılmasını gerektirmekte ve risk yönetimini zorunlu hale getirmektedir. Bankalar ekonomilerin sahip oldukları finansal kaynakları yönetme sorumluluklarını üstlenmektedirler. Bir bankada ortaya çıkabilecek finansal sıkıntı, sorumluluklarını yerine getirememe, iflas gibi problemler sadece banka yönetimi, hissedarlar ve çalışanları etkilememekte, mudiler, kaynak sağlayanlar, kredi kullananlar, bunlarla ilişkili üçüncü kişiler ve ekonomik yapı etkilenmektedir. Bankaların 
ekonomi içindeki bu konumlarından dolayı dünya genelinde risk yönetimiyle ilgili ilk standartlar ve düzenlemeler bankacilık alanında yapılmıştır.

Finansal aracı görevi yürüten bankaların ekonomik büyümede önemli rolü bulunmaktadır. Bu konuda Schumpeter (1911) finansal aracıların sağladıkları hizmetler yoluyla tasarrufları harekete geçirme, projeleri değerleme, riskleri yönetme ve yöneticileri izleme fonksiyonlarını gerçekleştirerek teknolojik yenilik ve ekonomik büyümeye imkan sağladıklarını ifade etmiştir (King ve Levine, 1993, s.717). Bundan başka Patrick (1966) bankaların ve finansal sistemin ekonomik büyüme amacıyla sermaye birikimi sağlayabilmesini üç temel yolla açıklamıştır: İlki, finansal kurumların varlık sahiplerinin sahipliklerinde ve varlık bileşimlerinde değişimler yaparak kaynak verimliliğinin artmasını teşvik etmesidir. İkincisi, finansal kurumlar tasarruf sahipleriyle girişimci yatırımcılar arasında aracılık yaparak kaynakların göreceli olarak daha üretken alanlarda kullanılmasını sağlayarak yeni yatırımlarda kaynak etkinliğinin sağlayabilir. Üçüncüsü ise, tasarruf ve yatırım teşviklerini artırarak sermaye birikiminin artmasını sağlayabilir.

Bankalar faaliyetlerini gerçekleştirirken karlılıklarını etkileyebilecek değişik nitelikte risklerle karşılaşmaktadırlar. Bu konuda Tevfik, bankacılık risklerini iç riskler (kredi riski, likidite riski, faiz oran riski, döviz kur riski, sermaye yetersizliği riski ve piyasa riski) ve diş riskler (hukuksal faktörler, politik faktörler, sosyal faktörler ve diğer faktörler) şeklinde ikiye ayırmıştır. Sufian (2011) banka karlılığının belirleyicilerini bankacilığa özgü faktörler ya da içsel belirleyiciler (likidite, sermaye yeterliliği, faiz gelirleri, faiz dışı gelirler, maliyet yönetimi gibi) ve dışsal belirleyiciler (sahiplik, büyüklük ve ekonomik koşullar gibi) şeklinde ikiye ayırırken Athanasoglou vd., (2008) ise banka karlılığını etkileyen faktörleri üç grupta açiklamıştır. Bunlar, bankacılığa özgü faktörler, endüstriye özgü faktörler ve makroekonomik faktörler şeklindedir. Bankacılığa özgü faktörler; kredi riski, verimlilik, gider yönetimi, büyüklük şeklinde; endüstriye özgü faktörler sahiplik yapısı ve rekabet; makroekonomik faktörler ise enflasyon ve iş döngüsü şeklinde belirtilmiştir. 
Bankacıların finansal yapılarından kaynaklı likidite, kredi, faiz ve döviz kuru gibi riskleri söz konusudur. Bu risklerin iki tür kaynağı söz konudur. İlki bankaların finansal pozisyonlarıdır. Likiditenin yükümlülükleri karşılayacak düzeyde olmaması ya da atıl likiditenin bulunması likidite riskini ortaya koymaktadır. Yeterli derecede inceleme ve değerleme yapılmadan kredi kullandırılması ya da kredi kullanımında aşırı kısıtlamalara gidilmesi kredi riskiyle ilgili sorunlardır. Mevduat sağlama ve kredi kullanımında vade uyumunun sağlanması ve sabit faizle borçlanmaların gerçekleştirilerek faiz oran riskinin düşürülmesi ya da mevduat-kredi arasında vade uyumsuzluğunun bulunması ve değişken faizle borçlanma tercihi ile faiz oran riskinin artırılması gibi durumlar faiz oran riskini işaret etmektedir. Döviz cinsinden aktiflerle pasifler arasında süre ve tutar bakımından uyumun sağlanması ya da döviz cinsinden varlık ve yükümlülükler arasındaki pozisyon açıklığı döviz kur riskini gösterir. İfade edilen bu riskleri ortaya çıaran finansal pozisyonlar banka yönetici ve karar alıcılarının uygulamalarına bağlı olarak değişebilmektedir.

İkinci risk kaynağı, bankaların finansal, yönetsel ve kurumsal yapılarının dışındaki sebeplerden kaynaklanan dişsal veya çevresel şeklinde nitelendirilebilecek ekonomik, politik, sosyal, hukuksal gibi risklerdir. Söz konusu risklere banka karar alıcılarının etkisi yoktur. Ancak banka yöneticileri bu tür riskleri yakından takip etmek, analiz etmek zorundadırlar. Çünkü, politik, ekonomik ve finansal olmak üzere bu tür riskler doğrudan ya da dolaylı olarak banka amaçlarını ve karlılığını etkileyebilmektedir. Ülkelerin ekonomik yapılarından kaynaklı büyüme, dış ticaret açığı, cari işlemler açığı, özel ve kamu olmak üzere ülke borç stoku gibi makroekonomik koşullar doğrudan doğruya döviz kurunu, faiz oranlarını etkileyebilmektedir. Döviz kuru ve faiz oranlarındaki değişimler bankaların finansal yapılarına göre banka karlılığını artırmakta ya da azaltmaktadırlar. Döviz kurundaki artış, döviz cinsinden varlıkları döviz cinsinden kaynaklarından daha fazla olan bankada kambiyo karları ortaya çıkarırken; aynı artış, döviz cinsinden varlıkları döviz cinsinden kaynaklarından az olan bankada ise kambiyo zararları meydana getirecektir. Faiz oranlarındaki artış, mevduatlarının vadesi kullandırdığı kredilerin vadesinden uzun olan bir bankanın faiz marjının azalmasına hatta negatif faiz marjının gerçekleşmesine neden olabilirken; bu artış 
mevduatların vadesi kredilerin vadesinden düşük olduğunda bankanın faiz marjı artacaktır.

Makroekonomik koşullar likidite ve kredi risklerini de etkileyebilmektedir. Ekonominin durgunluk dönemlerinde, mevduat sahiplerinin hesaplarından para talepleri, ihtiyaç sahiplerinin ise kredi talepleri artabilmekte, bankalar bu talepler karşısında likidite problemleri yaşayabilmektedirler. Yine bu durgunluk dönemlerinde, kredilerin faiz ve anapara geri ödemelerinde aksaklıklar artmaya başlamakta, kredi riskleri yükselmektedir.

Bunların dışında politik riskler, siyasal istikrar, geniş sosyal olaylar, grevler, yolsuzluk gibi etkenler bankacilık faaliyetlerini etkileyebilmektedir. Bu tür risklerde meydana gelen artışlar risk primlerini yükseltmekte, faiz ve döviz kur dalgalanmalarına neden olmakta, kişilerin finansal sistemden uzaklaşmalarına, tasarruf eğiliminin azalmasına zemin hazırlayabilmektedir.

1970'li yıllarda Bretton Woods sisteminin ortadan kalkmasıyla birlikte dünya genelinde ekonomik ve finansal risklerde artışlar görüldü. 1970'li yıllara kadar genellikle stabil şekilde hareket eden döviz kuru, faiz oranı ve emtia fiyatları gibi değişkenlerde Bretton Woods sisteminden sonra büyük oynaklıklar görülmeye başladı. 1973 ve 1980 yıllarında görülen petrol şokları da ekonomik ve finansal risklerin daha da artmasına yol açtı.

Günümüzde küreselleşme olgusu dünyanın büyük bir kısmında görülen, işletmeleri, yatırımcıları, finansal piyasaları, finansal kurumları, ekonomi yönetimlerini etkileyen temel olgu haline gelmiştir. Küreselleşmeyle birlikte sermaye hareketleri yükselmiş, fon transferleri hızlanmış, rekabet artmış, herhangi bir piyasada yaşanan ekonomik veya finansal bir sıkıntının başka ekonomi ya da piyasalara bulaşması hızlanmış, böylece ekonomik ve finansal riskler yükselmiştir. Dünya genelinde halka açık şirket sayıları artmış, borsalardaki yatırımcı sayıları yükselmiş, halka açık şirketlerin yatırımcıları bilgilendirme faaliyetleri genişlemiş bunlarla birlikte yatırımcıların risk yönetimiyle ilgili beklentileri yükselmiştir. Ortaya çıkan bu süreçler işletmelerin, finansal kurumların maruz kaldıkları riskleri daha iyi tanıma, ölçme, değerlendirme ve geçerli risk yanıtını verme gibi konulara daha fazla önem verme, risk yönetim uygulamalarını daha etkin hale getirmeleri zorunluluğunu ortaya çıkarmıştır. 
Tablo 1'de işletmelerin 2009-2017 döneminde ve 2020 tahmini olarak iş ve ekonomi dünyasının karşılaştıkları en yüksek 10 riskin sıralamasını vermektedir. Tablo değerleri, 1.843 farklı büyüklük ve endüstrideki organizasyonlardan dünya genelinde, 60 'dan fazla ülkeden elde edilen verilerden oluşturulmuştur.

Banka karlılıklarını etkileyen ekonomik değişkenlerin başında ekonomik büyüme gelmektedir. Küresel kriz öncesinde, 2007 yılında en büyük 10 risk siralamasında 8 . sirada bulunan ekonomik durgunluk ve yavaş toparlanma, küresel kriz sonrası dönemde 1 ve 2 . sıraya yükselmiş, 2020 beklentisinde ise ilk sırada bulunmaktadır. 2008 küresel finansal kriz sonrasında, genel olarak dünyada ekonomik durgunluk ve yavaş toparlanma söz konusudur. Küresel krizden önceki 8 yılda ortalama olarak $\% 2,8$ oranında büyüyen $\mathrm{ABD}$ ekonomisi, küresel krizden sonraki 8 yılda ortalama \%2,04 büyüme gerçekleştirmiştir. Küresel krizden önceki 8 yılda ortalama \%10,56 oranında büyüyen Çin ekonomisi küresel kriz sonrasındaki 8 yılda ortalama \%7,94 oranında büyümüştür. Aynı şekilde dünya ekonomisi küresel kriz öncesindeki 8 yılda ortalama olarak $\% 3,5$ büyüme gerçekleştirirken, küresel kriz sonrasındaki 8 yılda ortalama \%3 büyüme gerçekleştirmiştir.

Banka karlılıklarını etkileyebilecek ekonomik ve finansal diğer riskler de riskler sıralamasında görülmektedir. Bunlar artan rekabet, yenilik yapamama, müşteri ihtiyaçlarını karşılayamama, mevzuat ve yasal değişiklikler, politik riskler ve belirsizlikler, ürün fiyat riskleri şeklindedir. Ayrıca risk sıralamasını ilk 10'unda olmasa bile, ekonomik ve finansal risklerle ilgili listenin ilerleyen sıralarında bulunan başka riskler de bulunmaktadır. Bunlar 12. sırada nakit akışı ve likidite riski, 16. sırada döviz kur dalgalanmaları, 21. sırada kredi riski, 39. sırada faiz oran değişimleri, 40. sırada küreselleşme ve gelişen piyasalar, 46. sırada varlık değer dalgalanmaları, 50. sırada yabancı borç riskleri ve 52. sırada pay senedi fiyatındaki dalgalanma riskleridir (Aon, 2017, s.10). 
Tablo 1: En Yüksek 10 Risk

\begin{tabular}{|c|c|c|c|c|}
\hline 2011 & 2013 & 2015 & 2017 & 2020 (Tahmin) \\
\hline $\begin{array}{l}\text { Ekonomik Dur- } \\
\text { gunluk }\end{array}$ & $\begin{array}{l}\text { Ekonomik Dur- } \\
\text { gunluk ve Ya- } \\
\text { vaş } \\
\text { Topalanma }\end{array}$ & $\begin{array}{l}\text { Firma İtibarı ve } \\
\text { Markasının } \\
\text { Zarar Görmesi }\end{array}$ & $\begin{array}{l}\text { Firma İtibarı } \\
\text { ve } \\
\text { Markasının } \\
\text { Zarar Görmesi }\end{array}$ & $\begin{array}{l}\text { Ekonomik } \\
\text { Durgunluk ve } \\
\text { Yavaş } \\
\text { Toparlanma }\end{array}$ \\
\hline $\begin{array}{l}\text { Mevzuat ve } \\
\text { Yasal } \\
\text { Değişiklikler }\end{array}$ & $\begin{array}{l}\text { Mevzuat ve } \\
\text { Yasal } \\
\text { Değişiklikler }\end{array}$ & $\begin{array}{l}\text { Ekonomik } \\
\text { Durgunluk ve } \\
\text { Yavaş } \\
\text { Toparlanma }\end{array}$ & $\begin{array}{l}\text { Ekonomik } \\
\text { Durgunluk ve } \\
\text { Yavaş } \\
\text { Toparlanma }\end{array}$ & Artan Rekabet \\
\hline $\begin{array}{l}\text { Artan } \\
\text { Rekabet }\end{array}$ & $\begin{array}{l}\text { Artan } \\
\text { Rekabet }\end{array}$ & $\begin{array}{l}\text { Mevzuat ve Yasal } \\
\text { Değişiklikler }\end{array}$ & $\begin{array}{l}\text { Artan } \\
\text { Rekabet }\end{array}$ & $\begin{array}{l}\text { Yenilik } \\
\text { Yapamama/ } \\
\text { Müşteri } \\
\text { İhtiyaçlarını } \\
\text { Karşılayamama }\end{array}$ \\
\hline $\begin{array}{l}\text { Firma İtibarı ve } \\
\text { Markasının } \\
\text { Zarar Görmesi }\end{array}$ & $\begin{array}{l}\text { Firma } \\
\text { İtibarı ve Mar- } \\
\text { kasının Zarar } \\
\text { Görmesi } \\
\end{array}$ & $\begin{array}{l}\text { Artan } \\
\text { Rekabet }\end{array}$ & $\begin{array}{l}\text { Mevzuat ve } \\
\text { Yasal } \\
\text { Değişiklikler }\end{array}$ & $\begin{array}{l}\text { Mevzuat ve } \\
\text { Yasal } \\
\text { Değişiklikler }\end{array}$ \\
\hline İş Durması & $\begin{array}{l}\text { Kaliteli } \\
\text { İşgücünün } \\
\text { Cezbedile- } \\
\text { memesi veya } \\
\text { Tutulama- } \\
\text { masındaki } \\
\text { Başarısızlık }\end{array}$ & $\begin{array}{l}\text { Kaliteli İşgücünün } \\
\text { Cezbedilememesi } \\
\text { veya } \\
\text { Tutulamamasındaki } \\
\text { Başarısızlık }\end{array}$ & $\begin{array}{l}\text { Bilişim } \\
\text { Suçu/Hekleme/ } \\
\text { Virüsler/ } \\
\text { Zararlı } \\
\text { Yazılımlar }\end{array}$ & $\begin{array}{l}\text { Bilişim Suçu/ } \\
\text { Hekleme/ } \\
\text { Virüsler/ } \\
\text { Zararlı Yazılımlar }\end{array}$ \\
\hline $\begin{array}{l}\text { Yenilik Yapa- } \\
\text { mama/ Müşteri } \\
\text { İhtiyaçlarını } \\
\text { Karşılayamama }\end{array}$ & $\begin{array}{l}\text { Yenilik Yapa- } \\
\text { mama/ Müşteri } \\
\text { İhtiyaçlarını } \\
\text { Karşılayamama }\end{array}$ & $\begin{array}{l}\text { Yenilik Yapamama/ } \\
\text { Müşteri İhtiyaçlarını } \\
\text { Karşılayamama }\end{array}$ & $\begin{array}{l}\text { Yenilik Yapa- } \\
\text { mama/ Müşteri } \\
\text { İhtiyaçlarını } \\
\text { Karşılaya- } \\
\text { mama }\end{array}$ & $\begin{array}{l}\text { Firma İtibarı ve } \\
\text { Markasının Zarar } \\
\text { Görmesi }\end{array}$ \\
\hline $\begin{array}{l}\text { Kaliteli } \\
\text { İşü̈cünün } \\
\text { Cezbedile- } \\
\text { memesi veya } \\
\text { Tutulama- } \\
\text { masındaki } \\
\text { Başarısızlık }\end{array}$ & $\begin{array}{l}\text { İş } \\
\text { Durması }\end{array}$ & $\begin{array}{l}\text { İş } \\
\text { Durması }\end{array}$ & $\begin{array}{l}\text { Üst } \\
\text { Düzey } \\
\text { Yetenekleri } \\
\text { Çekememek/ } \\
\text { Koruyamamak }\end{array}$ & $\begin{array}{l}\text { Üst } \\
\text { Düzey } \\
\text { Yetenekleri Çeke- } \\
\text { memek } \\
\text { /Koruyamamak }\end{array}$ \\
\hline $\begin{array}{l}\text { Ticari Mal- } \\
\text { lardaki Fiyat } \\
\text { Riskleri } \\
\end{array}$ & $\begin{array}{l}\text { Ticari } \\
\text { Mallardaki Fi- } \\
\text { yat Riskleri } \\
\end{array}$ & $\begin{array}{l}\text { Üçüncü } \\
\text { Şahıslara } \\
\text { karşı Sorumluluk }\end{array}$ & $\begin{array}{l}\text { İş } \\
\text { Kesintisi }\end{array}$ & $\begin{array}{l}\text { Politik Riskler/ } \\
\text { Belirsizlikler }\end{array}$ \\
\hline $\begin{array}{l}\text { Teknoloji ve Sis- } \\
\text { tem } \\
\text { Başarısızlıkları }\end{array}$ & $\begin{array}{l}\text { Nakit } \\
\text { Akışı/Likidite } \\
\text { Riskleri } \\
\end{array}$ & $\begin{array}{l}\text { Bilişim Suçu/Hek- } \\
\text { leme/Virüsler/ } \\
\text { Zararlı Yazılımlar }\end{array}$ & $\begin{array}{l}\text { Politik Riskler/ } \\
\text { Belirsizlikler }\end{array}$ & $\begin{array}{l}\text { Ürün } \\
\text { Fiyat Riskleri }\end{array}$ \\
\hline $\begin{array}{l}\text { Nakit } \\
\text { Akış1/Likidite } \\
\text { Riskleri }\end{array}$ & $\begin{array}{l}\text { Politik } \\
\text { Riskler/ } \\
\text { Belirsizlikler }\end{array}$ & $\begin{array}{l}\text { Mal } \\
\text { Zararları }\end{array}$ & $\begin{array}{l}\text { Üçüncü Şahıs } \\
\text { Sorumlulukları }\end{array}$ & $\begin{array}{l}\text { Yıkıcı } \\
\text { Teknolojiler/ } \\
\text { Yenilikler }\end{array}$ \\
\hline
\end{tabular}

Kaynak: (Aon Risk Solutions, 2017, s. 17.) 


\section{Literatür}

$\mathrm{Bu}$ çalışmada ekonomik ve finansal ülke risklerinin banka karlılıklarına etkisi araştırılmıştır. Literatürde kullanılan değişkenler ve amaç bakımından bu çalışmayla birebir benzerlik gösteren çalışma şu ana kadar yapılan araştırmalara göre bulunamamıştır. Literatürde benzerlik gösteren çalışmalar, banka karlılığını etkileyen faktörler çalışmaları, risk faktörlerinin değişik nitelikte değişkenlere etkilerinin araştırıldığ çalışmalar ve bankaların kendi yapılarından kaynaklı olarak ortaya çıkan risklerle karlılık arasındaki ilişkileri araştıran çalışmalar şeklinde üç farklı grupta toplanabilir.

Literatürde banka karlılık belirleyicilerinin neler olduğuna yönelik birçok çalışma bulunmaktadır. Bu çalışmalarda genellikle bankaların finansal, yönetsel ve kurumsal yapılarından kaynaklı bankacılığa özgü faktörlerin ve makroekonomik koşulların karlılık üzerine etkileri araştırılmıştır. Bu nitelikteki çalışmalar içinde tarih olarak eski olduğu kadar kullandığı değişken kapsamı ve örneklem bakımından geniş çalışma Demirgüç-Kunt ve Huizinga (1999) tarafından yapılmıştır. DemirgüçKunt ve Huizinga (1999) 1988-1995 döneminde 80 ülkeden elde edilen banka seviyesindeki verileri kullanarak faiz marjları ve banka karlılığını belirleyicilerini bankacılığa özgü değişkenler, makroekonomik değişkenler, doğrudan ve dolaylı banka vergilendirmesi, mevduat sigorta düzenlemesi, genel finansal yap1 ve kurumsal faktörleri esas alarak araştırmışlardır. Çalışmada, sahiplik yapısı, vergilendirme, finansal yapı, hukukun üstünlüğü, yolsuzluk gibi kurumsal faktörlerin banka faiz marjı ve banka karlılığını belirleyicileri olduğu, faiz gelirleri, faiz giderleri, faiz dışı gelirler, faiz dışı giderler gibi bankacılık değişkenlerinin karlılığı etkilediği görülmüştür.

685 banka gibi geniş örneklem ve kapsamlı değişkenler kullanarak Staikouras ve Wood (2004) 1994-1998 döneminde Avrupa Birliği'nde (AB) banka karlılığı etkileyen faktörleri araştırmışlardır. Elde edilen sonuçlar AB Bankacılığında karlılı̆̆ın hem iç faktörler hem de dış faktörlerden etkilendiğini ortaya koymaktadır. Daha yüksek özkaynağın daha fazla karlılığa yol açtığı, kredi/varlıklar oranının aktif karlılığıyla ters yönde ilişkili olduğu, banka büyüklügünün büyük bankaları negatif, küçük 
bankaları pozitif, faiz oranlarının büyük bankaları negatif, küçük bankaları pozitif etkilediği tespit edilmiştir.

Athanasoglou vd., (2008) ise, bankalara özgü, endüstriye özgü ve makroekonomik faktörler çerçevesinde 1985-2001 döneminde Yunanistan bankaları örnekleminde karlılığın belirleyicilerini araştırmışlardır. Elde edilen sonuçlar, sermayenin önemli karlılık belirleyicisi olduğunu, kredi riskinin karlılığı azalttığını, işgücü verimliliğinin karlılığı artırdığını, faaliyet giderlerinin karlılığı olumsuz etkilediğini göstermiştir. Benzer şekilde Sufian (2011) tek ülke verilerini kullanarak, 1992-2003 döneminde Güney Kore örneğinde banka karlılığını etkileyen faktörleri bankacılı̆̆a özgü etkenler ve makroekonomik etkenler şeklinde araştırmıştır. Çalışmada, daha düşük likidite seviyesinde bankaların daha yüksek karlılık gösterdikleri, bankaların gelir kaynaklarını türev ürünler ve ücrete dayalı faaliyetler gibi çeşitlendirmesinin karlılığa pozitif etkisinin olduğunu, genel giderler ve kredi riskinin karlılığa etkisinin negatif olduğu, Asya krizinin etkisinin negatif olduğu, kriz sonrasına göre krizden önce daha fazla karlılığın bulunduğu belirlenmiştir.

Michalopoulos ve Tsermenidis (2018), Ocak 2003-Haziran 2015 döneminde, Euro Bölgesi'nde, banka borçlanma maliyet dağılımını etkileyen ülke risk faktörlerini, küresel, finansal ve Euro borç krizinin etkilerini de dikkate alarak araştırmışlardır. Ülke riskleri devlet tahvili faizleriyle ölçümlenmiştir. Sonuçlar, devlet tahvili risklerinin banka borçlanma maliyet dağılımlarını etkilemediği ancak küresel kriz ve Euro borç krizi döneminde borçlanma maliyet dağılımının kötüleştiği görülmüştür.

Topak ve Talu (2016), Küçükbay (2017), Güzel ve İltaş (2018) ve Denizli vd., (2018) çalı̧̧malarında ise Türkiye örnekleminde banka karlılığını etkileyen faktörler araştırılmıştır. Topak ve Talu (2016) Ocak 2006:Q1 - Mart 2014:Q2 döneminde, çeyrek dönemlik verileri kullanarak Türkiye'deki 12 ticari bankanın karlılıklarını etkileyen faktörleri araştırmışlardır. Çalışmada, net ücret ve komisyon gelirlerinin toplam giderlere oranı ve kredi faizlerinin mevduat faizlerine oranlarının aktif karlılığ ve özkaynak karlılığına etkilerinin pozitif oldukları, diğer faaliyet giderlerinin toplam faaliyet giderlerine oranı ve büyüklüğün karlılığa etkisinin negatif olduğu görülmüştür.

Güzel ve İltaş (2018) 2003-2016 dönemine ait 13 ticari bankayı esas alarak Türkiye'de banka karlılı̆̆ını belirleyicilerini araştırmışlarıdır. 
Çalışmada likidite ve faaliyet dışı gelirler oranlarının banka karlılığına pozitif etkisi görülürken, takipteki krediler ve diğer faaliyet giderleri oranlarını negatif etkisi elde edilmiştir. Küçükbay (2017) 2009-2013 döneminde Türkiye'de faaliyette bulunan bankaların karlılıklarını etkileyen faktörleri araştırmıştır. Sermaye oranı ve banka büyüklügünün banka karlılığını, kredi oranı ve sermaye oranının ise net faiz marjını etkilediği görülmüştür. Denizli vd., (2018) 2005-2017 döneminde, Türkiye'de aktif büyüklügü en büyük olan 9 banka örnekleminde faiz gelirlerindeki artışın banka karlılığını artırdığı, faiz dışı gelirlerin ise banka karlılığına etkisinin negatif olduğunu görmüşlerdir.

Bankaların özellikle finansal yapılarından kaynaklı kredi, döviz kur, likidite gibi riskler söz konusudur. Özellikle kredi riski başta olmak üzere bu risklerin banka karlılığına etkisinin arandığı çalışmalar söz konusudur. Bikker ve Vervliet (2017), düşük faiz koşullarının ABD bankacılık sektörü üzerine etkisini karlılık ve risk alma açısından incelemişlerdir. Çalışmada düşük faiz ortamının banka performansına zarar verdiği ve net faiz marjını azalttığı, genel olarak kredi riskinin ve risk ağırlıklı sermaye rasyosunun karlılığa etkisinin negatif olduğu, büyüklüğün net faiz marjına etkisinin olumsuz buna karşın karlılığa etkisi olumlu olduğu görülmüştür. Benzer nitelikte Delis ve Kouretas (2011), 2001-2008 döneminde, Euro Bölgesinde 16 ülkeden elde ettikleri verileri kullanarak düşük faiz oranlarının bankaların risk almalarını önemli derecede artırdığını görmüşlerdir.

Karaca ve Uğur (2008) 2002-2005 döneminde Türkiye'de banka karlılığını etkileyen faktörlere ilişkin çalışmalarında iflas riski ve kredi riskinin banka karlılığını olumsuz etkilediği banka büyüklügünün ise pozitif etkilediğini belirlemişlerdir. Tan (2016) 2003-2011 döneminde, Çin'de faaliyette bulunan 41 ticari banka üzerinde, bankacılık risk ve rekabetin karlılık üzerine etkisini araştırmıştır. Risk ve rekabetin bankacılık karlılığını etkilemediği sonucuna ulaşılmıştır.

Banka büyüklüğünün banka karlılığına etkisiyle ilgili yapılan çalışmalardan farklı sonuçlar söz konusu olmakla birlikte, genel olarak banka büyüklüğünün banka karlılığını artırdığı görülmüştür. Demirgüç-Kunt ve Huizinga (1999), Goddard vd., (2004) ve Borio vd., (2015) çalışmalarında büyüklüğün banka karlılığınına pozitif etkisi görülürken, Topak 
ve Talu (2016), Bikker ve Vervliet (2017) ve Denizli vd, (2018) çalışmalarında büyüklüğün banka karlılığına negatif etkisini elde etmiştir. Benzer şekilde Shehzad vd., (2013) büyük bankaların küçük bankalardan daha karlı olduğunu belirlemiştir. Öte yandan Athanasoglou vd., (2008) ve Trujillo-Ponce (2013) çalışmalarında büyüklüğün karlılık üzerine olumlu ya da olumsuz etkisi tespit edilememiştir (Bikker ve Vervliet, 2017: 4).

$\mathrm{Bu}$ çalışmada ekonomik ve finansal ülke risklerin etkileri araştırılmıştır. Literatürde banka karlılığına olmasa da, söz konusu ülke risklerinin açıklayıcı değişken olarak kullanıldığı çalışmalar söz konusudur. Bu çalışmalarda genellikle ülke risklerinin pay senetlerine etkileri araştırılmıştır. Erb vd., (1996) politik, ekonomik ve finansal risk faktörlerinin beklenen pay senedi getirileriyle ilişkili olup olmadığını araştırmışlardır. Ülke risk ölçümlerinin gelecekteki pay senedi getirileri ve pay senedi değerleriyle ilişkili olduğu anlaşılmıştır.

Hassan vd., (2003) 1984-1999 döneminde, Orta Doğu ve Afrika'daki 10 menkul kıymet borsası verilerini kullanarak politik, ekonomik ve finansal risklerin borsa endekslerindeki fiyat oynaklığını nasıl etkilediğini, endeks öngörülebilirliği ve portföy çeşitlendirme konularını araştırmışlardır. Çalışmada politik, ekonomik ve finansal risk faktörlerinin oynaklık parametrelerini değiştirdiği; bu risk faktörlerinin Orta Doğu ve Afrika'daki gelişmekte olan ülke borsalarının öngörülebilirliğinde önemli güce sahip olduğu; bu ülke menkul kıymetlerinin çeşitlendirilmiş portföye dahil edildiğinde portföy riskinin azalacağı görülmüştür.

Kara ve Karabıyık (2015) 1999:01-2013:12 döneminde, politik, ekonomik ve finansal risk değişkenleri ile BİST 100 endeksi arasındaki ilişkiyi araştırmışlardır. Çalışmada, risk primlerinden hisse senedi fiyatlarına doğru bir nedenselliğin olduğu, ülke risk primlerinin hisse senedi fiyatlarını olumsuz etkiledikleri belirlenmiştir.

Ayaydın vd., (2016) 2002:M01-2015M12 dönemlerine ait aylık veriler yardımıyla Türkiye için hesaplanan ekonomik, politik ve finansal riskler ile BİST 100 endeksi arasındaki ilişkiyi incelemişlerdir. Çalışma sonuçları pay senedi getirileriyle ekonomik, politik ve finansal riskler arasında negatif yönlü bir ilişki olduğunu göstermiştir. İlişkinin yönüne bakıldığında ise ekonomik büyüme ile pay getirileri arasında çift yönlü, finansal ve politik risklerle pay senedi getirileri arasında tek yönlü ilişki görülmüştür. 
Girard (2018) ülke risk derecelendirmelerini kullanarak hisse senedi risk primi hesaplamak için bir metodoloji ortaya koymuştur. Çalışmada 85 sermaye piyasası verileri, Fama ve French küresel risk primi ve ICRG'nin politik, ekonomik ve finansal risk göstergeleri Ocak 1985 ve Ocak 2017 dönemi için kullanılmıştır. Ortaya konulan pay senedi risk primi mevcut risk primleriyle karşılaştırılmış ve daha önce kalibre edilmiş risk primleriyle geliştirilen risk primi arasında istatistiksel açıdan fark olmadığı gözlemlenmiştir.

Lee vd., (2014) Asya'da 22 ülke düzeyinde 967 bankadan elde ettikleri verileri kullanarak faiz dışı gelirlerin banka karlılığı ve banka risklerine olan etkilerini araştırmışlardır. Çalışmada Asya bankalarının faiz dışı faaliyetlerinin riskleri azalttığı ancak karlılığ1 artırmadığı, risk sürekliliğinin banka özellikleri ve ülke gelir seviyelerinden etkilendiği görülmüş̧ür.

Zaremba (2018) 75 ülke borsasından elde edilen aylık verilerle, ülke riskleriyle pay senetleri piyasalarında beklenen getiriler arasındaki ilişkiyi keşfetmeyi amaçlamıştır. Ülke risklerini temsilen The Economist Intelligence Unit tarafından hazırlanan risk göstergeleri kullanılan çalışmada, küresel pay senetleri piyasalarında ülke risklerinin fiyatlandırıldığı, riskgetiri ilişkisinin dış borçlanma, ekonomik yapı ve bankacılık sektörü tarafından belirlendiği buna karşın kur riskinin getirilerle ilişkili olmadığı görülmüştür.

\section{Yöntem}

Ülkelere ait ekonomik ve finansal riskler, Uluslararası Ülke Risk Rehberi (International Country Risk Guide- ICRG), PRS Grup tarafından yayımlanmaktadır. Ekonomik riskler; Kişi Başı GSYİH, GSYİH Büyüme Oranı, Yıllık Enflasyon, Bütçe Dengesi/GSYİH ve Cari Hesap Dengesi/GSYİH şeklindedir. Finansal Riskler ise Dış Borç/GSYİH, Dış Borç Servisi/İhracat, Cari Hesap/İhracat, İthalata Ödenen Net Likidite ve Döviz Kuru İstikrarı şeklindedir. Dünya Bankası (World Bank - Global Financial Development) ise ülke düzeyinde, bankacllık sektörünün vergi sonrası aktif karlılık oranlarını (AKO) ve özkaynak karlılık oranlarını yayımlamaktadır. Bu çalışmada ifade edilen iki veri kaynağı kullanılarak, ülkelere ait ekonomik ve finansal risklerin banka karlılıklarına etkisi 
araştırılmıştır. Çalışma dönemi 2001-2016 şeklinde oluşturulmuştur. Özellikle banka karlılık oranları verilerin tarihsel olarak ileriye gidememesi, çalışma döneminin belirleyicisi olmuştur. Çalışma örneklemi dünyanın değişik bölgeleri ve dünya genelinde değişik ekonomik gelişmişlik düzeyine sahip 44 ülkeden² oluşturulmuştur.

Tablo 2: Özet İstatistikler

\begin{tabular}{lllllll}
\hline Değişkenler & $\begin{array}{l}\text { Gözlem } \\
\text { Sayısı }\end{array}$ & Ortalama & Ortanca & Maksimum & $\begin{array}{l}\text { Mini- } \\
\text { mum }\end{array}$ & $\begin{array}{l}\text { Std. } \\
\text { Sapma }\end{array}$ \\
\hline AKO & 704 & 0.878758 & 0.883537 & 4.020970 & -8.522210 & 1.053139 \\
\hline OKA & 704 & 10.95999 & 12.20415 & 34.49600 & -85.06420 & 10.78629 \\
\hline $\begin{array}{l}\text { Döviz Kuru } \\
\text { İstikrarı }\end{array}$ & 704 & 1.702652 & 1.291667 & 10.16667 & 1.000000 & 1.066343 \\
\hline $\begin{array}{l}\text { Cari } \\
\text { Hesap/ihracat }\end{array}$ & 704 & 3.901870 & 3.750000 & 8.500000 & 1.000000 & 1.272759 \\
\hline $\begin{array}{l}\text { İthalata } \\
\begin{array}{l}\text { Ödenen } \\
\text { Net Likidite }\end{array}\end{array}$ & 704 & 3.758049 & 4.000000 & 6.000000 & 1.000000 & 1.353933 \\
\hline $\begin{array}{l}\text { Diş Borç } \\
\text { Servisi/Ihracat }\end{array}$ & 704 & 2.153883 & 1.750000 & 10.00000 & 1.000000 & 1.348038 \\
\hline $\begin{array}{l}\text { Yıllık Enflasyon } \\
\text { Bütçe }\end{array}$ & 1.974077 & 1.645833 & 7.833333 & 1.000000 & 1.070537 \\
\hline $\begin{array}{l}\text { Dengesi/GSYİH } \\
\text { Cari Hesap } \\
\text { Dengesi/GSYİH }\end{array}$ & 704 & 4.391809 & 4.500000 & 9.458333 & 1.000000 & 1.562944 \\
\hline & 4.093928 & 4.250000 & 13.20833 & 1.000000 & 1.807620 \\
\hline
\end{tabular}

Tablo 2'de çalışmada kullanılan değişkenlere ilişkin özet istatistikler görülmektedir. Örneklem bankalarının ortalama aktif karlılık oranları (AKO) \%0,87, özkaynak karlılık oranları (OKO) ise \%10,9'dur. Görüldüğü üzere iki karlılık oranı arasında önemli düzeyde farklılıklar söz konusudur. Bankalar özkaynaklarının birkaç katı oranında kaynak sağlayıp bunu varlıklara (krediler gibi) çevirdiklerinden özkaynakları ile varlık toplamları arasında büyük farklılıklar olabilmektedir. Bu nedenler özkaynak karlılık oranıla varlık karlılık oranı arasında \%10,03 oranında (\%10,9 $\% 0,87)$ farklılıkların olması normal karşılanabilir.

\footnotetext{
${ }^{2}$ Bu ülkeler; Arjantin, Avustralya, Bangladeș, Brezilya, Kanada, Çin, Danimarka, Mısır, Finlandiya, Fransa, Almanya, Hindistan, Endonezya, Israil, italya, Güney Kore, Malezya, Meksika, Hollanda, Norveç, Pakistan, Panama, Filipinler, Portekiz, Singapur, Güney Afrika, Ispanya, Isveş, Isviçre, Tayland, Türkiye, Ingiltere, $A B D$, Avusturya, Belçika, Şili, Yunanistan, Japonya, Yeni Zelanda, Suudi Arabistan, Birleşik Arap Emirlikleri, Macaristan, Paraguay ve Romanya'dan oluşmaktadır.
} 
Tablo 3. Korelasyon Matrisi

\begin{tabular}{|c|c|c|c|c|c|c|}
\hline Değişkenler & $\mathrm{AKO}$ & OKA & $\begin{array}{l}\text { Döviz } \\
\text { Kuru } \\
\text { İstikrarı }\end{array}$ & $\begin{array}{l}\text { Cari Hesap/ } \\
\text { İhracat }\end{array}$ & $\begin{array}{l}\text { İthalata } \\
\text { Ödenen } \\
\text { Net } \\
\text { Likidite }\end{array}$ & $\begin{array}{l}\text { DışBorç } \\
\text { Servisi/İhracat }\end{array}$ \\
\hline $\mathrm{AKO}$ & 1 & & & & & \\
\hline OKA & $\begin{array}{l}0,856 \\
(0,00 \\
0) \\
\end{array}$ & 1 & & & & \\
\hline $\begin{array}{l}\text { Döviz } \\
\text { Kuru İstikrarı }\end{array}$ & $\begin{array}{l}- \\
0,158 \\
(0,00 \\
0)\end{array}$ & $\begin{array}{l}- \\
0,137 \\
(0,00 \\
0) \\
\end{array}$ & 1 & & & \\
\hline $\begin{array}{l}\text { Cari Hesap/ } \\
\text { İhracat }\end{array}$ & $\begin{array}{l}- \\
0,023 \\
(0,54 \\
6) \\
\end{array}$ & $\begin{array}{l}- \\
0,018 \\
(0,63 \\
6) \\
\end{array}$ & $\begin{array}{l}0,225 \\
(0,000)\end{array}$ & 1 & & \\
\hline $\begin{array}{l}\text { İthalata } \\
\text { Ödenen } \\
\text { Net Likidite }\end{array}$ & $\begin{array}{l}- \\
0,162 \\
(0,00 \\
0) \\
\end{array}$ & $\begin{array}{l}- \\
0,138 \\
(0,00 \\
0) \\
\end{array}$ & $\begin{array}{l}0,068 \\
(0,071)\end{array}$ & $\begin{array}{l}0,343 \\
(0,000)\end{array}$ & 1 & \\
\hline $\begin{array}{l}\text { DişBorç } \\
\text { Servisi/ } \\
\text { İhracat }\end{array}$ & $\begin{array}{l}- \\
0,148 \\
(0,00 \\
0)\end{array}$ & $\begin{array}{l}- \\
0,105 \\
(0,00 \\
5)\end{array}$ & $\begin{array}{l}0,197 \\
(0,000)\end{array}$ & $\begin{array}{l}0,325 \\
(0,000)\end{array}$ & $\begin{array}{l}0,230 \\
(0,000)\end{array}$ & 1 \\
\hline Değişkenler & $\mathrm{AKO}$ & OKA & $\begin{array}{l}\text { Ylllık } \\
\text { Enflasyon }\end{array}$ & $\begin{array}{l}\text { Bütçe Dengesi/ } \\
\text { GSYİH }\end{array}$ & $\begin{array}{l}\text { Cari } \\
\text { Hesap } \\
\text { Dengesi/ } \\
\text { GSYİH } \\
\end{array}$ & \\
\hline $\begin{array}{l}\text { Yillik } \\
\text { Enflasyon }\end{array}$ & $\begin{array}{l}0,228 \\
(0,00 \\
0) \\
\end{array}$ & $\begin{array}{l}0,152 \\
(0,00 \\
0) \\
\end{array}$ & 1 & & & \\
\hline $\begin{array}{l}\text { Bütçe } \\
\text { Dengesi/GSY } \\
\text { İH }\end{array}$ & $\begin{array}{l}- \\
0,166 \\
(0,00 \\
0)\end{array}$ & $\begin{array}{l}- \\
0,174 \\
(0,00 \\
0)\end{array}$ & $\begin{array}{l}0,214 \\
(0,000)\end{array}$ & 1 & & \\
\hline $\begin{array}{l}\text { Cari } \\
\text { Hesap } \\
\text { Dengesi/ } \\
\text { GSYİH } \\
\end{array}$ & $\begin{array}{l}- \\
0,018 \\
(0,62 \\
5)\end{array}$ & $\begin{array}{l}- \\
0,014 \\
(0,70 \\
8) \\
\end{array}$ & $\begin{array}{l}0,200 \\
(0,000)\end{array}$ & $\begin{array}{l}0,371 \\
(0,000)\end{array}$ & 1 & \\
\hline
\end{tabular}

ICRG tarafından yayımlanan risk göstergelerinde düşük not yüksek riski, yüksek not ise düşük riski temsil etmektedir. Risk ölçüm literatürüyle uyumlu olma ve değişkenlerin katsayı işaretlerinin doğru yorumlanabilmesi için ICRG'nin risk sıralaması değiştirilerek düşük notun düşük riski, yüksek notun yüksek riski göstermesi sağlanmış ve risk 
göstergeleri oluşturulan bu sıralamayla analize tabi tutulmuştur. Tablo 2'de görüldüğü üzere risk ölçüm değerleri 1'den (minumum risk) başlayıp gittikçe artmaktadır. Tablo 3'de Pearson korelasyon katsayıları görülmektedir. Buna göre, finansal risk göstergeleri olan döviz kuru istikrarı, ithalata ödenen net likidite, dış borç servisi/ihracat risklerinin banka karlılık oranlarıyla ters yönde korelasyonlu oldukları; ekonomik risklerde ise, enflasyon riskinin banka karlılıklarıyla pozitif yönde, bütçe dengesi/GSYİH riskinin negatif yönde korelasyonlu olduğu görülmektedir.

Küreselleşme, uluslararası ticaret ve finansal entegrasyonun yüksek derecede olması, ekonomik dalgalanmaların diğer ülkelere yayılmasına neden olduğundan panel nedensellik analizlerinde ülkeler arasındaki yatay kesit bağımlılıklarının dikkate alınması önemlidir. Eğer nedensellik analizine dahil edilen ülkeler arasında yüksek entegrasyon derecesi varsa, yatay kesit bağımlılığını göz ardı ederek yapılan nedensellik analizleri önemli derecede sapmalı ve büyük çarpıklıklara neden olabilir (Pan vd., 2015, s.447).

Tablo 4'deki yatay kesit bağımlılık test sonuçlarına göre döviz kuru istikrarı ve dış borç servisi/ihracat değişkenlerine I. nesil, diğerlerine II. Nesil birim kök testleri uygulanmıştır.

Tablo 4. Yatay Kesit Bağımlılık Testleri

\begin{tabular}{lllll}
\hline Değişkenler & $\begin{array}{l}\text { Breusch- } \\
\text { Pagan LM }\end{array}$ & $\begin{array}{l}\text { Pesaran } \\
\text { scaled LM }\end{array}$ & $\begin{array}{l}\text { Bias- } \\
\text { Corrected } \\
\text { scaled LM }\end{array}$ & Pesaran CD \\
\hline AKO & $\begin{array}{l}1969.097 \\
(0,0000)\end{array}$ & $\begin{array}{l}23.52102 \\
(0,0000)\end{array}$ & $\begin{array}{l}22.05435 \\
(0,0000)\end{array}$ & $\begin{array}{l}18.27705 \\
(0,0000)\end{array}$ \\
\hline OKA & 2080.152 & 26.07418 & 24.60752 & 18.17003 \\
$(0,0000)$ & $(0,0000)$ & $(0,0000)$ \\
\hline $\begin{array}{l}\text { Döviz Kuru } \\
\text { İtikrarı }\end{array}$ & NA & NA & NA & NA \\
\hline Cari Hesap/İhracat & $\begin{array}{l}2724.978 \\
(0,0000)\end{array}$ & $\begin{array}{l}40.89874 \\
(0,0000)\end{array}$ & $\begin{array}{l}39.43207 \\
(0,0000)\end{array}$ & $\begin{array}{l}2.505676 \\
(0,0122)\end{array}$ \\
\hline İthalata Ödenen & 3315.310 & 54.47050 & 53.00384 & 12.74038 \\
Net Likidite & $(0,0000)$ & $(0,0000)$ & $(0,0000)$ & $(0,0000)$ \\
\hline $\begin{array}{l}\text { Diş Borç } \\
\text { Servisi/İhracat }\end{array}$ & NA & NA & NA & NA \\
\hline Y1llk Enflasyon & 2217.235 & 29.22572 & 27.75905 & 22.16779 \\
\hline
\end{tabular}




\begin{tabular}{|c|c|c|c|c|}
\hline & $(0,0000)$ & $(0,0000)$ & $(0,0000)$ & $(0,0000)$ \\
\hline Bütçe & 3442.009 & 57.38330 & 55.91663 & 31.02577 \\
\hline Dengesi/GSYİH & $(0,0000)$ & $(0,0000)$ & $(0,0000)$ & $(0,0000)$ \\
\hline Hesap & 2602.439 & 38.08157 & 36.61490 & 3.406904 \\
\hline Dengesi/GSYİH & $(0,0000)$ & $(0,0000)$ & $(0,0000)$ & $(0,0007)$ \\
\hline
\end{tabular}

Tablo 5: Pesaran CADF Birim Kök Testi

\begin{tabular}{|c|c|c|c|c|c|}
\hline Değişkenler & $\mathrm{AKO}$ & OKA & $\begin{array}{l}\text { İthalata } \\
\text { Ödenen } \\
\text { Net } \\
\text { Likidite }\end{array}$ & $\begin{array}{l}\text { Yillık } \\
\text { Enflasyon }\end{array}$ & $\begin{array}{l}\text { Bütçe } \\
\text { Dengesi/GSYİH }\end{array}$ \\
\hline Düzey & $\begin{array}{l}-2.794 \\
(0,000) \\
\end{array}$ & $\begin{array}{l}-2.925 \\
(0,000) \\
\end{array}$ & $\begin{array}{l}-2.058 \\
(0,016) \\
\end{array}$ & $\begin{array}{l}-2.459 \\
(0,000) \\
\end{array}$ & $\begin{array}{l}-2.005 \\
(0,000) \\
\end{array}$ \\
\hline $\begin{array}{l}\text { Kritik } \\
\text { Değerler }\end{array}$ & $\% 1$ & $-2.250, \quad \% 5$ & -2.110 & $\% 10 \quad-2.030$ & \\
\hline
\end{tabular}

Tablo 5 ve Tablo 6'da II. nesil birim kök testlerinden Pesaran CADF ve Panicca birim kök test sonuçları görülmektedir. Test sonuçları değişkenlerin düzeyde durağan olduklarını, birim kök içermediklerini ifade etmektedir.

Tablo 6: Panicca Birim Kök Testi

\begin{tabular}{lllll}
\hline Düzey & ADF Test & $\mathbf{P a}_{\mathbf{a}}$ & $\mathbf{P}_{\mathbf{b}}$ & PMSB \\
\hline Cari & -3.434 & -5.91 & -3.467 & -2.256 \\
Hesap/İhracat & $(0,0012)$ & $(0,0000)$ & $(0,0003)$ & $(0,012)$ \\
\hline Cari Hesap & -2.945 & -6.416 & -3.562 & -2.349 \\
Dengesi/GSYİH & $(0,0032)$ & $(0,0000)$ & $(0,0002)$ & $(0,0094)$ \\
\hline
\end{tabular}

Not: Parantez içindeki değerler olasılıkları göstermektedir.

Tablo 7 'de ise I. nesil birim kök testleri görülmektedir. Burada da değişkenlerin düzeyde durağan oldukları görülmektedir.

Panel veri analizinde uygun model seçimlerinin belirlenmesinde $\mathrm{F}$ testi, Olabilirlik Oranı (LR) testi ve Hausman testleri kullanılmaktadır. F testi ve Olabilirlik Oranı (LR) testleri klasik (Havuzlandırılmış) modelin kabul veya reddinde kullanılmaktadır. " $\mathrm{H}_{0}=$ Klasik (Havuzlandırılmış Regresyon) Model Geçerlidir" hipotezi LR testleriyle \%5 önem düzeyinde 
test edilmiştir. Sabit ve rassal etki modellerinin geçerlilikleri ise Hausman testleriyle belirlenmiştir.

Tablo 7. I. Nesil Birim Kök Testleri

\begin{tabular}{lllll}
\hline \multirow{2}{*}{ Değişkenler } & $\begin{array}{l}\text { Levin, Lin } \\
\text { \& Chu }\end{array}$ & $\begin{array}{l}\text { Im, } \\
\text { Pesaran } \\
\text { ve Shin }\end{array}$ & ADF - Fisher & PP - Fisher \\
\cline { 2 - 5 } & Düzeyde & & & 370.641 \\
\hline Döviz Kuru & -16.7377 & -13.2633 & 322.508 & $(0,0000)$ \\
İstikrarı & $(0,0000)$ & $(0,0000)$ & $(0,0000)$ & 174.955 \\
\hline DişBorç & -10.7627 & -5.72166 & 137.708 & $(0,0000)$ \\
Servisi/İhracat & $(0,0000)$ & $(0,0000)$ & $(0,0001)$ & \\
\hline
\end{tabular}

Not: Parantez içindeki değerler olasılıkları göstermektedir.

Panel veri analizinde uygun model belirleme aşamasından sonra model varsayım testlerinin yapılması gerekmektedir. Bu testler, değişen varyans, otokorelasyon ve birimler arası korelasyon testleridir. Sabit etkiler modelinde değişen varyans için Değiştirilmiş Wald testi, otokorelasyon için Bhargava, Franzini ve Narendranathan tarafından önerilen Durbin-Watson testi, birimler arası korelasyon için ise $(\mathrm{N}>\mathrm{T})$ koşulu altında Pesaran CD testi kullanılmıştır.

\section{Bulgular}

LR testleri ve Hausman testi neticesinde sabit etki modeli uygun model olarak belirlenmiş, varsayım testlerinde ise değişen varyans ve birimler arası korelasyon tespit edilmiştir. Modelde değişen varyans, otokorelasyon ve birimler arası korelasyondan en az birisini varlığı halinde $t$ ve $F$ istatistiklerinin ve $\mathrm{R}^{2}$ 'nin geçerlilikleri etkilenmektedir. Bu durumların varlığı halinde dirençli standart hatalar elde edilmeli ya da uygun tahmin yöntemleri kullanılmalıdır (Yerdelen Tatoğlu, 2013: 242). Bu sebeplerle çalışmada Driscoll ve Kraay dirençli tahminci yöntemi kullanılmıştır. 
Tablo 8: Finansal Risklerin Banka Karlılıklarına Etkisi, Driscoll ve Kraay Dirençli Tahmincisi

\begin{tabular}{|c|c|c|c|c|c|c|}
\hline \multirow{2}{*}{ Değişkenler } & \multicolumn{3}{|l|}{ AKO } & \multicolumn{3}{|l|}{ OKO } \\
\hline & Katsayı & Std. Hata & Olasılık & Katsayı & Std. Hata & Olasılık \\
\hline Sabit & 1.481657 & 0.5142778 & 0.011 & 14.53161 & 5.116436 & 0.012 \\
\hline $\begin{array}{l}\text { Döviz } \\
\text { Kuru İstikrarı }\end{array}$ & -0.2405572 & 0.1133263 & 0.051 & -2.234172 & 0.9305502 & 0.030 \\
\hline $\begin{array}{l}\text { Cari } \\
\text { Hesap/Ihracat }\end{array}$ & 0.0477018 & 0.0396357 & 0.247 & 0.5372921 & 0.381039 & 0.179 \\
\hline $\begin{array}{l}\text { İthalata } \\
\text { Ödenen } \\
\text { Net Likidite }\end{array}$ & 0.0161564 & 0.0770393 & 0.837 & 0.2364939 & 0.8041135 & 0.773 \\
\hline $\begin{array}{lr}\text { Diş } & \text { Borç } \\
\text { Servisi/IIhracat } \\
\end{array}$ & -0.2043085 & 0.0436727 & 0.000 & -1.277597 & 0.4853843 & 0.019 \\
\hline $\begin{array}{l}\text { LR Testi } \\
\text { Birim Etki } \\
\text { Zaman Etki } \\
\text { Birim ve } \\
\text { Zaman Etki }\end{array}$ & $\begin{array}{l}217.285(0, \\
8.112(0,00) \\
237.420(0,0\end{array}$ & & & $\begin{array}{l}102.964(0, \\
29.401(0,0 \\
145.868(0,\end{array}$ & & \\
\hline $\begin{array}{l}\text { Hausman } \\
\text { Testi }\end{array}$ & $17.67(0,00$ & & & $13.67(0,00$ & & \\
\hline Wald Test & $4006.41(0,0$ & & & $3235.30(0$, & 00) & \\
\hline $\begin{array}{l}\text { Durbin- } \\
\text { Watson }\end{array}$ & 1.0603016 & & & 1.225414 & & \\
\hline Pesaran CD & $11.318(0,0)$ & & & $14.518(0,0$ & & \\
\hline Gözlem Sayısı & 704 & & & 704 & & \\
\hline $\mathrm{R}^{2}$ & 0,13 & & & 0,07 & & \\
\hline Olasılik $>\mathrm{F}$ & 0.0031 & & & 0.0031 & & \\
\hline
\end{tabular}

Çalışmada etkisi aranılan dört adet finansal risk göstergesinden ikisinin banka karlılıklarına etkisi görülmüştür (Tablo 8). Döviz kuru istikrarı ve dış borç servisi/ihracat değişkenleri banka karlılıkları olan aktif karlılık oranı (AKO) ve özkaynak karlılık oranını (OKO) negatif yönde etkilemişlerdir. Bankalar finansal yapıları gereğince döviz kur riskine ve faiz oran riskine maruz kalmaktadırlar. Bu çerçevede döviz kuru istikrarı ya da istikrarsızlığı ile yurt dışı borçlanma, banka karlılıklarını olumsuz etkileyebilmektedir. Yurt dışı borçlanma sadece faiz oran riskini ortaya çıkarmamakta, aynı zamanda döviz kur riskini de içermektedir.

Ekonomik risklerden bütçe dengesi/GSYİH ve cari hesap dengesi/GSYİH değişkenlerinin banka karlılıklarını etkiledikleri görülmektedir. Bütçe dengesi/GSYİH değişkeni banka karlılıklarını 
olumlu yönde etkilerken, cari hesap dengesi/GSYİH değişkeni olumsuz yönde etkilemiştir. Bütçe dengesi kamu bütçe dengesini gösterirken, cari hesap dengesi ülkenin tahsilat ve ödemelerinden meydana gelen nakit dengesidir. Cari hesap dengesinin diğer risk göstergelerinden farklı olarak banka karlılıklarını pozitif yönde etkilemesi, örneklem ülkeleri cari dengelerinin fazla verdiği ve bu nedenle etkisinin pozitif olduğu şeklinde değerlendirilebilir.

Tablo 9: Ekonomik Risklerin Banka Karlılıklarına Etkisi, Driscoll ve Kraay Dirençli Tahmincisi

\begin{tabular}{|c|c|c|c|c|c|c|}
\hline \multirow{2}{*}{ Değişkenler } & \multicolumn{3}{|l|}{$\mathrm{AKO}$} & \multicolumn{3}{|l|}{$\mathrm{OKO}$} \\
\hline & Katsayı & Std. Hata & Olasılik & Katsayı & Std. Hata & Olasılık \\
\hline Sabit & 1.144533 & 0.5031284 & 0.038 & 15.31732 & 4.681925 & 0.005 \\
\hline Yillık Enflasyon & $\begin{array}{l}- \\
0.0762118\end{array}$ & 0.1193968 & 0.533 & $\begin{array}{l}- \\
0.9206938\end{array}$ & 1.129616 & 0.428 \\
\hline $\begin{array}{l}\text { Bütçe } \\
\text { Dengesi/GSYİH }\end{array}$ & $\begin{array}{l}- \\
0.1090764 \\
\end{array}$ & 0.028235 & 0.002 & -1.319686 & 0.3256435 & 0.001 \\
\hline $\begin{array}{lr}\text { Cari } & \text { Hesap } \\
\text { Dengesi/GSYİH } \\
\end{array}$ & 0.0888431 & 0.0500909 & 0.096 & 0.7954722 & 0.4183176 & 0.077 \\
\hline $\begin{array}{l}\text { LR Testi } \\
\text { Birim Etki } \\
\text { Zaman Etki } \\
\text { Birim ve Zaman } \\
\text { Etki }\end{array}$ & \multicolumn{3}{|c|}{$\begin{array}{l}123.511(0,000) \\
21.844(0,000) \\
153.234(0,000)\end{array}$} & \multicolumn{3}{|c|}{$\begin{array}{l}62.283(0,000) \\
35.118(0,000) \\
108.268(0,000)\end{array}$} \\
\hline Hausman Testi & \multicolumn{3}{|c|}{$36.05(0,0000)$} & \multicolumn{3}{|c|}{$23.58(0,0000)$} \\
\hline Wald Test & \multicolumn{3}{|c|}{$8256.85(0,0000)$} & \multicolumn{3}{|c|}{$8488.47(0,0000)$} \\
\hline Durbin-Watson & \multicolumn{3}{|l|}{0.98384779} & \multicolumn{3}{|l|}{1.1824453} \\
\hline Pesaran CD & \multicolumn{3}{|c|}{$20.032(0,0000)$} & \multicolumn{3}{|c|}{$18.573(0,0000)$} \\
\hline Gözlem Sayısı & \multicolumn{3}{|l|}{704} & \multicolumn{3}{|l|}{704} \\
\hline $\mathrm{R}^{2}$ & \multicolumn{3}{|l|}{0,03} & \multicolumn{3}{|l|}{0,03} \\
\hline Olasılık $>\mathrm{F}$ & \multicolumn{3}{|l|}{0.0291} & \multicolumn{3}{|l|}{0.0001} \\
\hline
\end{tabular}

Bu çalışmada, banka karlılıklarının belirlenmesinde dişsal faktörler şeklinde nitelendirilebilecek ekonomik ve finansal ülke risklerinin banka karlılıklarına etkisi belirlenmiştir. Literatürdeki çalışmaların bazılarında da dışsal etkenlerin banka karlılıklarını etkilediği görülmüştür. Bu çalışma sonucuna kısmen benzerlik gösteren çalışmalarda; Staikouras ve Wood (2004) faiz oranları etkisini, Sufian (2011) Asya krizinin etkisini, Topak ve Talu (2016) faiz oranları etkisini, Bikker ve Vervliet (2017) düşük faiz oranları etkisini, Delis ve Kouretas (2011) düşük faiz oranlarının 
banka risk almalarına etkilerini belirlemişlerdir. Buna karşın Michapoulos ve Tresmenidis (2018) devlet tahvili risklerinin banka borçlanma maliyetlerini etkilemediğini görmüşlerdir. Dolayısıyla bu çalışma bulgularıyla Michapoulos ve Tresmenidis (2018) çalışması bulguları farklı sonuçlar ortaya koymaktadir.

\section{Sonuç}

Bankaların ekonomik yapı içindeki fonksiyonlarını devam ettirmeleri, ülke kaynaklarının doğru alanlara etkin şekilde aktarılması, tasarrufların teşvik edilmesi gibi konular ülke ekonomileri açısından önemlidir. Bankaların bu fonksiyonları yapabilmeleri, onların varlıklarını sürdürmelerine, amaçlarını gerçekleştirmelerine yani kar sağlamalarına bağlıdır. Banka karlılıkları banka yöneticilerin karar ve uygulamalarıyla ifade edilen içsel faktörlere bağlı olduğu kadar, banka yöneticilerinin kontrolleri dışındaki dışsal faktörlere de bağlıdır. Ülkelerin döviz kurları, borçlanmaları, piyasa likidite koşulları, bütçe dengeleri, cari dengeleri gibi finansal ve ekonomik koşullarına bağlı olarak ortaya çıkan riskler banka karlılıklarını etkileyebilmektedir.

Bu çalışmada, 2001-2016 döneminde 44 ülkeden elde edilen veriler yardımıyla banka karlılıklarını etkileyen ekonomik ve finansal riskler araştırılmıştır. Döviz kuru istikrarı, dış borç servisi/ihracat ve bütçe dengesi/GSYİH değişkenleriyle ifade edilen risklerin banka karlılıklarını negatif yönde etkilerken cari hesap dengesi/GSYİH değişkeniyle gösterilen risk faktörünün ise banka karlılıklarını pozitif yönde etkilediği tespit edilmiştir.

Ortaya çıan bu sonuçlar, banka yönetimleri, risk yöneticileri, yatırımcılar, finansal piyasaları ve finansal kurumları geliştirmek isteyen ekonomik yönetimleri açısından kullanabilirlik taşımaktadır. Bu noktada bankaların içsel risk faktörlerinin yanında dışsal risk faktörlerini de dikkate almaları, ekonomik ve finansal yapıyla ilgili riskleri iyi analiz etmeleri, bu risklerle ilgili gelişmeleri yakından takip etmeleri bu çalışmanın ortaya koyduğu önemli sonuçlardan biridir. 


\title{
EXTENDED ABSTRACT
}

\section{Impact of Economic and Financial Country Risks on Bank Profitability}

\author{
Zekai Şenol
}

Sivas Cumhuriyet University

Banking is transfering obtained resources with a surplus to those requesting funds with a certain cost or costless from fund provider. Banks are financial institutions performing various services with their physical infrastructure, and they are the oldest and most important institute of financial system. Although many financial institutions of different nature and function have emerged within the financial system, banking is still one of the most basic institutions of the financial system.

Bank management is a risk management activity as of general characteristics. Even though as of the system is expressed in a short and easy way in terms of providing deposits and transferring credits in essence, banking necessitates encountering very different and important risks and necessitates risk management.

Banks face to various risks that may affect their profitability when carrying out their activities. Banking risks can be divided into two: internalist risks (credit risk, liquidity risk, interest rate risk, exchange rate risk, insufficient capital risk and market risk) and externalist risks (legal factors, political factors, social factors and other factors).

External risks are risks such as economic, political, social, legal that may be characterized as external or environmental due to reasons other than the financial, administrative and institutional structures of banks. Decision takers in banks have no influence on these risks. However, bank managers must closely monitor and analyze such risks. Because, such risks may directly or indirectly affect bank objectives and profitability, political, economic or financial. Macroeconomic conditions such as growth due to economic structures of countries, foreign trade deficit, current account deficit, public and private debt stock can directly affect exchange 
rate and interest rates. Changes in exchange rates and interest rates increase or decrease bank profitability according to the financial structure of banks. While the increase in the exchange rate uncover foreign exchange profits at banks whose foreign currency assets are more than their foreign currency sources; the same increase results in foreign exchange losses in the bank whose foreign currency assets are less than the foreign currency sources. While the increase in interest rates may lead to a decrease in the interest margin or even a negative interest margin of a bank whose maturities are longer than the maturity of the loans extended by their deposits; this increase will increase the interest margin of the bank when the maturity of the deposits is lower than the maturity of the loans.

Macroeconomic conditions may also affect liquidity and credit risks. Money requests from depositors' accounts, credit demands of the needy may increase during the recession periods of the economy, and banks may have liquidity problems in response to these demands. Again in these recession periods, problems in principal repayments of loans and interest rate start to increase and thus credit risks increase.

Except those, such as political risks, political stability, broad social events, strikes and corruption may affect banking activities. Increases in such risks increase risk premiums, cause interest and exchange rate fluctuations, and prepare the ground for people to move away from the financial system and decrease the saving tendency.

\section{Method}

In this study, the effects of economic and financial country risks on bank profitability were investigated. Data were obtained from International Country Risk Guide (ICRG), PRS Group and World Bank (Global Financial Development). Economic risks; Per capita GDP, GDP Growth Rate, Annual Inflation, Budget Balance/GDP and Current Account Balance/GDP. Financial Risks are Foreign Debt/GDP, Foreign Debt Service/Export, Current Account/Export, International Liquidity and Exchange Rate Stability. The bank's return on assets (ROA) and return on equity (ROE) were used to represent the bank's profitability. The study consisted sampling of 44 countries and the period 2001-2016. Panel data analysis was used in the study. 


\section{Results}

In the study, two of the four financial risk indicators whose effects were sought had an impact on bank profitability. Exchange rate stability and external debt service / export variables negatively affected the bank profitability return on asset (ROA) and return on equity (ROE). Banks are exposed to exchange rate risk and interest rate risk due to their financial structure. In this context, exchange rate stability or instability and foreign borrowing may adversely affect bank profitability. Foreign borrowing not only creates interest rate risk, also includes exchange rate risk.

The budget balance/GDP and current account balance/GDP variables from economic risks affect on bank profitability. While budget balance / GDP variable positively affect on bank profitability, current account balance / GDP variable had a negative effect. While the budget balance represents the public budget balance, the current account balance is the cash balance consisting of the country's collections and payments. Unlike other risk indicators, current account balance positively affects bank profitability, in these sample countries, current account balances having a surplus and therefore can evaluate have a positive effect. These results are usable in terms of bank management, risk managers, investors, economic management who want to develop financial markets and financial institutions. At this point, it is one of the important results of this study that banks take into account internal risk factors as well as external risk factors, analyze the risks related to economic and financial structure and follow the developments related to these risks closely.

\section{Kaynakça / References}

Aon Risk Solutions. (2017). Global risk management survey.

Athanasoglou, P. P., Brissimis, S. N., ve Delis, M. D. (2008). Bank-specific, industry-specific and macroeconomic determinants of bank profitability. Journal of International Financial Markets, Institutions and Money, 18(2), 121-136. 
Ayaydın, H., Pala, F. ve Barut, A. (2016). Ülke riskinin hisse senedi getirisine etkisi: Ampirik bir analiz. Küresel İktisat ve Isşletme Çalışmaları Dergisi, 5(10), 66-75.

Bikker, J. A. ve Vervliet, T. M. (2017). Bank profitability and risk-taking under low interest rates. International Journal of Finance $\mathcal{E}$ Economics, 23(1), 3-18.

Delis, M. D. ve Kouretas, G. P. (2011). Interest rates and bank risk-taking. Journal of BankingEFinance, 35(4), 840-855.

Demirgüç-Kunt, A. ve Huizinga, H. (1999), Determinants of commercial bank interest margins and profitability: Some international evidence, The World Bank Economic Review, 13(2), 379-408.

Denizli, K. G., Koç, S. ve Şenol, Z. (2018). Bankacılık değişkenleri ile performans göstergeleri arasındaki ilişkinin panel veri yönetimi ile analizi: Türkiye örneği (2005-2017). Sosyal Bilimler Dergisi, 5(30), 565-579.

Erb, C. B., Harvey, C. R. ve Viskanta, T. E. (1996). Political risk, economic risk and financial risk. Financial Analysts Journal, 52(6), 29-46.

Girard, E. (2018). How does country risk matter?. Journal of Global Business \& Technology, 14(1), 53-67.

Güzel, A. ve İltaş, Y. (2018). Ticari bankalarda karlılığın belirleyicileri: Türkiye örneği (2003-2016). Ankara Hacı Bayram Veli Üniversitesi İ̈BF Dergisi, 20(3), 505-534.

Hassan, M. K., Maroney, N. C., El-Sady, H. M. ve Telfah, A. (2003). Country risk and stock market volatility, predictability and diversification in the Middle East and Africa. Economic Systems, 27(1), 6382.

Kara, E. ve Karabiyık, L. (2015). The effect of country risk on stock prices: an application in Borsa Istanbul. Süleyman Demirel Üniversitesi İ̈BF Dergisi, 20(1), 225-239.

Karaca, S., ve Uğur, A. (2008), Türkiye'deki bankacıllk sektöründe risk ve karlılık analizi. World of Accounting Science, 10(3), 123-134.

King, R. G. ve Levine, R. (1993). Finance and growth: Schumpeter might be right. The Quarterly Journal of Economics, 108(3), 717-737.

Küçükbay, F. (2017), Banka karlılığını etkileyen faktörler: Avrupa Birliği bankaları ve Türk bankaları arasında bir karşılaştırma. Yönetim ve Ekonomi, 24(1), 137-149. 
Lee, C. C., Yang, S. J. ve Chang, C. H. (2014). Non-interest income, profitability and risk in banking industry: A cross-country analysis. North American Journal of Economic and Finance, 27, 48-67.

Michalopoulos, G. ve Tsermenidis, K. (2018). Country risk on the bank borrowing cost dispersion within the Euro Area during the financial and debt crises. International Journal of Economics and Business Administration, 6(4), 76-92.

Pan, C-I., Chang, T. ve Wolde-Rufael, Y. (2015). Military spending and economic growth in the middle east countries: Bootstrap panel causality test. Defence and Peace Economics, 26(4), 443-456.

Patrick, H. T. (1966). Financial development and economics growth in underdevelopment countries. Economic Development \& Cultural Change, 14(2), 174-189

Staikouras, C. K. ve Wood, G. E. (2004), The determinants of European bank profitability. International BusinessEEconomics Research Journal, 3(6), 57-68.

Sufian, F. (2011), Profitability of the Korean banking sector: Panel evidence on bank-specific and macroeconomic determinants. Journal of Economics and Management, 7(1), 43-72.

Tan, Y. (2016), The impact of risk and competition on bank prifitability in China. Journal of International Financial Markets, InstitutionsEMoney, 40, 85-110.

Topak, M. S. ve Talu, N. H. (2016), Internal determinents of bank profitability: Evidence from Turkish banking sector. International Journal of Economic Pespectives, 10(1), 37-49.

Yerdelen-Tatoğlu, F. (2013), Panel veri ekonometrisi: Stata Uygulamalı. İstanbul: Beta Basım Yayım.

Zaremba, A. (2018), Country risk and expected return across global equity markets. Journal of Economic and Finance, 68(4), 374-398.

https://databank.worldbank.org/data/source/global-financial-development, 04.01.2019.

https://www.prsgroup.com/explore-our-products/international-countryrisk-guide/, 06.08.2018. 


\section{Kaynakça Bilgisi / Citation Information}

Şenol, Z. (2019). Ekonomik ve finansal ülke risklerin banka karlılığına etkisi. OPUS-Uluslararası Toplum Araştırmaları Dergisi, 12(18. UİK Özel Sayıs1), 890-916. DOI: 10.26466/opus.601090 